\title{
Special issue: 2018 Quebec elections
}

\author{
Amy G. Mazur ${ }^{1}$ \\ Published online: 24 June 2020 \\ (c) Springer Nature Limited 2020
}

This is my third issue as lead editor and I must say I am very proud of it in many ways. The special issue on the 2018 Quebec Elections is an "issue to remember." The political science done here is outstanding thanks to the excellent and hard work of the authors, reviewers and the leadership of the editors, Eric Belanger and JeanFrancois Daoust. It has been a true pleasure working with Eric and Jean-François and their team; all timely, hard-working and extremely responsive.

This is methodologically cutting-edge work that displays a range of methods and theoretical approaches-experimental, high-level statistical analysis and modeling, theoretical dialog between political philosophy and political science. Moreover, taken together, the special issue is a mixed methods study, given that the articles employ quantitative methods and the pieces as a whole are a case study in the dynamics and determinants of electoral shifts. As such, this collection of coordinated articles has much to offer comparativists and students of Quebec politics alike. Indeed, this issue makes the statement loud and clear that we publish work on politics in francophone countries as well as France.

The two articles that accompany this powerful special issue are also at a high level of excellence, thanks to the hard work of our review editor Isabelle Guinaudeau. Isabelle has recruited two up and coming scholars to write pieces for this issue, as well as many others for previous issues to produce important and meaningful review essays for the study of French Politics, Comparative Politics and the discipline more broadly speaking. Her diligence makes my job a true pleasure. And with this issue, we are introducing a new section on book reviews with timely assessments conducted by top scholars on several books with similar themes. This kickoff book review, by Estelle Badie, is on two books that contribute to our understanding of the Europeanization of National Parliaments in Italy and France. And our review essay is highly topical, by Pietro Castelli, for these volatile political times; on scholarship on the extreme right.

Reflecting the success and intellectual vibrancy of the study of French Politics, Vincent Pons and I, as Co-conveners of the French Politics-AFSP group of the American Political Science Association have worked with political scientists from

Amy G. Mazur

mazur@wsu.edu

1 Washington State University, Pullman, Washington, USA 
all over the world to put together a series of panels for APSA's upcoming meetings in September in San Francisco. As with other professional associations, APSA has made the tough decision to put online the meetings. The group has decided to delay the memorial roundtable for Robert Elgie to the 2021 meetings in San Francisco. Read more updates on the FPG-AFSP group at the end of this issue in the FPG news section.

Our authors, editors and reviewers have continued their work for the journal despite the challenges presented by COVID 19 and, for that, I am incredibly grateful and recognizant; yet another indicator of the health of our field and of the journal. I hope that all of our readers, reviewers, authors and editors, their friends and family have been safe and sound and continue on this path in these highly challenging times.

And as always, please share with me your feedback, criticisms and/or concerns.

Amy G. Mazur, Lead Editor

Moscow, Idaho

June 23rd, 2020

Publisher's Note Springer Nature remains neutral with regard to jurisdictional claims in published maps and institutional affiliations. 